\title{
The Art of Traditional Painting in Assam: a Critical Study on the Manuscript Paintings of Bhagavata-Purana, VI-VII
}

\author{
Bikramjit Sarkar ${ }^{1}$, Dr. Rajesh Bhowmik ${ }^{2}$ \\ ${ }^{1}$ Research Scholar, Department of Fine arts, Tripura University. Orcid id: oooo-oooz- \\ 2752-86o1. Email id: bikramjitsarkar1983@gmail.com \\ ${ }^{2}$ Associate Professor, Department of Fine arts, Tripura University
}

\begin{abstract}
The art of manuscript painting Assam mostly developed during the medieval periods in response to the Bhakti-movement headed by the Vaisnava saint Srimanta Sankardeva (1449-1568). The establishments of Vaisnavite institutions so-called Satra in Assam were the major centres of practising manuscript paintings. The subject of the paintings is taken from the Hindu epic and Puranas. Different stories and events related to Lord Krishna were illustrated using Natural ingredients. The practice of paintings followed traditionally during $16^{\text {th }}$ to $19^{\text {th }}$ century. Especially different parts of BhagavataPurana were illustrated with paintings for entertainment and the better understanding of the people. The skill and quality of artists and their aesthetic sense of vision were executed through the paintings. This present paper has been made to highlight the paintings of Bhagavata-Prana VI-VII, which were executed during 1785 A.D. The skill of artists in the arrangement of composition and the simple stylistic representation is the matter of appreciation and understanding. It is very important to study and document the paintings in today's context of dying traditional knowledge of art practice so that the future generation can attain knowledge of the culture of painting in the development of society \& religion and also be aware of the contribution of the antiquities of past art and culture of North-East India.
\end{abstract}

Keywords: Assam, Bhagavata-Purana-VI-VII, Culture, Manuscript Painting, Tradition, Vaisnavism.

\section{Introduction}

In Assam the tradition of Painting mainly developed within the surface of manuscripts during the $16^{\text {th }}$ century A.D. "It is known that the art was practised in the satras, and in the courts of the Ahom-Koch kings under their patronage." The Vaisnava monasteries or institutions established by the great reformer of bhakti-movement Srimanta Sankardeva (1449- 1568 A.D.). These Vaisnavite institutions are locally termed as Satra in Assam. In the Satra premises, different art activities had been practised such as writing, performing dance, drama, song, mask making, sculpture and painting for the propagation of Bhakti (devotion) and the massage of Bhagavata among the people of Assam. One of the most significant features of the movement is the worship of religious scripture in the form of manuscript instead of any Idol form. This bhakti movement gave birth to a culture of practising the art of manuscript painting. The paintings illustrated numerous stories and chapters taken from the great Hindu epics Ramayana, Mahabharata and above all subject from the BhagavataPurana. The paintings of the Bhagavata-Purana mainly concentrate to depict different stories and events related to the supreme God Lord Krishna. "The manuscript leaves in Assam were made of two materials. Sanchipat or the thicker variety was made from the bark of Saci tree or aloeswood, Aquilaria agallocha. The preparation entitled a

(C) AesthetixMS 2016. This Open Access article is published under a Creative Commons Attribution NonCommercial 4.0 International License (http://creativecommons.org/licenses/by-nc/4.o/), which permits noncommercial re-use, distribution, and reproduction in any medium, provided the original work is properly cited. For citation use the DOI. For commercial re-use, please contact editor@chitrolekha.com 
laborious process of curing, seasoning and polishing the raw slices before the leaves could be made to retain the ink". ${ }^{2}$ Tulapat (handmade paper) is another type surface made of pressed cotton. Supporting on this two surfaces large number of manuscript paintings had been done between $16^{\text {th }}$ to $19^{\text {th }}$ centuries in Assam. "The Katha Guru Charita, the biography of Sri Sankardeva, gives Harital or orpiment and Hengul or Hingul as the two main colours used by the saint to paint the scenes of Chinha Yatra as well as for painting the manuscript cases." 3 Haital and Hengul are the most common in the traditional colour palates of manuscript painting. Haital or Harital is yellow arsenic used to get yellow colour and Hengul is used to get vermilion. This present study is based on the paintings of a volume of the manuscript titled Bhagavata-Purana,VI-VII, which has been executed in the year 1785 A.D. (1707saka ) in Assam.

\section{Result and Discussion}

2.1. General Description

The volume of manuscripts Bhagavata-Purana, part VI-VII consist 116 folios including 3 (three) paintings. Introduction of different floral border design is common in every folio except one. The size of the volume has been measured $39.3 \mathrm{~cm}$ in length and 11 $\mathrm{cm}$ in breadth. The language of the manuscripts is Sanskrit.

This volume of manuscripts has been found from the Karchong Satra in Nagaon district of Assam. Now the whole Volume is in a state of preventive conservation performed by field lab, Srimanta Sankardeva Kalakshetra, Panjabari, Guwahati-37 \& National Mission for Manuscript, New Delhi and kept under the custody of Srimanta Sankardev Research Institute of Nagaon in Assam.

\subsection{Pictorial Depiction of the paintings}

Through the study of the Bhagavata-Purana part-VI, it is found that the painting (Fig.1) depicts the story of a Vedic Brahmin Ajamila. The painting expressed the incident occurred during and after the Ajamila's death. The departed body is tied up and trying to take under the custody of three Yamdutas (the messenger of the god of death) to punish him for his connection in bad activities during his life. In the same time, four Vishnuduta's (the messengers of Lord Vishnu) have appeared to give relief Ajamila from the Yamduta's. In this painting, there was a young child named Narayana had been placed in the middle section of this painting. According to the Ajamila-upakhyan, as mentioned in the Bhagavata-Purana part-VI, the boy has been identified as the youngest child of Ajamila. Ajamila's love and affection towards child Narayana are more than the other child. Hence, during departing to death, Ajamila speak loudly to call Narayana to come near to him. Narayana is another name of Lord Vishnu and for uttering the name he was rescued from Yamdutas by the four Vishnudutas. Ultimately, the painting shows a glory of the lord Vishnu.

In the second painting (Fig 2), there is a depiction of different vignette design particularly based on foliage. The artist had composed two distinct varieties of unknown flowers and leafs. Despite the fact, there is some resemblance has been observed between the portrayed flower and flower-bearing plants with the local flower and flower-bearing plants found in Assam. 
The third paintings (Fig.3) of the book depicted a scene where the image of Vishnu has been portrayed seating in a simple cross-legged position with usual Sanka, Chakra, Gada, the Padma in his hands. The painting contained the posture of two standing male and two seated female figures. Naren Kalita opined that "the third miniature depicting a scene in Vaikuntha may be the work of another artist not a proficient as his counterpart who painted the other two miniatures." 4 But no justification and identification have been made on the subject and object of the paintings. Studying the Bhagavata-Purana chapter- XV of part-III, sloka (hymns) 27,28,33,34, the two same ages male figures with four hands in the painting can be identified as the illustrative image of Joy and Vijoy. They are the two of the attendants of Vaikunthanath as well as the gatekeeper of the abode of Visnu. It has been found in chapter IX of part - VI particularly from the sloka number 29-30, that the lord Visnu having sixteen personal attendants with same visual appearances like Visnu and they are said to be the DemiGod of Vaikuntha. Their physical appearances have also been described in the sloka number 27 of chapter XV in part- III. Same appearances of this two male figures portrayed between the two arched doors claim to be the image of Joy and Vijoy. Similar appearances of the image of Joy and Vijoy have been found in Satriya wood carvings certainly on the doors of different Vaisnava Sattras and Namghars (Fig.4). As an example, such images of Joy and Vijoy have been represented on the doors of Patbausi and Ganakuchi Sattra of Barpeta district in Assam with mentioning their respective names. It can be assumed that the depiction of the image of Joy and Vijoy on doors of Vaisnava monasteries is the idea taken from Puranas. The two seated female figure has been identified as the female attendant of Lord Visnu. Among the two female attendants, one has been portrayed in a knee-bending position in the lower right side of the image of Visnu with a pair of chowries in her hands. In the verses 35-43 of Bhagavata-Purana chapter XV of part- III, the chowries (fly whisk) have been described as the bright wings of a swan used as a hand fan. But artist used simple yellow lines to depict the chowries in this painting. It has been studied that the chowrie (fly whisk) has been used as one of the important elements in Hindu and Buddhist religion. "The fly-whisk is evident in some configurations of the Astamangala, employed in some traditions of murti puja, particularly the Gaudiya Vaishnava". ${ }^{5}$ The Gaudiya Vaisnavism is a Vaishnava religious movement inaugurated by Chaitanya Mahaprabhu (1486-1534) in the region of Gauda present day in Bangladesh with the same philosophy of worshipping Vishnu or Krishna and their many incarnations. But the basic source of idea of this movement is Bhagavata-Gita and Bhagavata-Purana same as the contemporary Bhakti movement of Sankardeva in Assam. The chowrie as an attribute or elements connected to Lord Vishnu has been visually depicted in this painting of Bhagavata-Purana in Assam. Another female attendant has been portrayed in a cross leg setting position down to the left side of the image of Visnu with a musical instrument in her hands. This musical instrument can be identified as violin because in the right hand of the attendant keeps a bow like an instrument which is generally used to play the violin. The character of these instruments has been portrayed as violin with a bow. It has been observed that the form of the portrayed instruments violin and bow are closer to some extent of Assamese bin. "Bin is one of the oldest traditional musical instruments of Assam. It is one of the Eight musical instrument used in Bihu" (Fig.5). The artist of this painting might have used this long neck form of the Assamese bin and bow in his own style to 
represents the women musician of the abode of Lord Vishnu with the instrument like bin and bow in her hand. An image of a bird-like creature has been portrayed right to the seated image Vishnu. It is found in the chapter- XVII of Bhagavata-Purana X that Garuda served as a vehicle of Lord Vishnu and sloka (hymn) - 18, chapter- XXI, part-I of Garuda-Purana suggested that Garuda is a kind of bird. In the painting (fig:3) the artist depicted a bird-like image right to the lord Vishnu which visually appears like the image of a king of bird eagle. The artist also tried to depict the bird vehicle of Lord Vishnu to illustrate the abode of Lord Vishnu Vaikunta so that the drawing of a birdlike creature in the painting can be identified as the image of the mythical bird Garuda.

\subsection{Arrangement of design and composition of the painting}

First of all the artist has chosen a rectangular shape of space for the paintings (Fig.1). The depicted figures placed vertically on the horizontal line or plane. Graphically, the arrangement of figures drawings vertically on the horizontal planes shows stability and balanced in composition (Fig.6). There is an absence of perspective in the painting and application of flat colour as a background is remains as one of the character and style of Satriya manuscript paintings. The facial expression and movement of the body show the aggressive mental and physical characteristic of the individual Yamdutas. The muscularity of the body of Yamdutas has been toned up by using a variety of parallel, cross and broken hatching, which visually creates gradations and shades on the body so that the figures appear with the aesthetic of mass and volume. The artist of this painting must be aware of the knowledge of tone, shade and hatching to express their aesthetic sense of vision or imagination to represent the aggressive character of Yamdutas. Artist also used bold curve hatching line to show the toned or bulkiness of the muscles of certain areas of the body. The curl wavy high-top hairstyle, the handlebar moustache, large eyes, broad nose, dark brown colour of the body, lifting of eyebrows and overall movement of the body parts aesthetically represents the furious and aggressive nature of the Yamdutas. On the other side, the figure of the Vishnudutas appeared with a normal facial expression which can be said as mild, soft, and pitying expression. The Vishndutas have been painted in a closing feet standing position with as usual four beautiful hands holding Conch, Lotus, Wheel (Chakra or discus) and Mace (Gada). The blue complexion and the iconographical representation of the Vishnu show that they are the four emissaries of Lord Vishnu. The figures of the Brahmin Ajamila and the child Narayana have been depicted gracefully with brooding facial expression. The drawings of the feet's of depicted figures of Vishnudutas, Yamdutas, Ajamila and child Narayana are proportionally large. Compare to the feet of other figures, the feet of the Ajamila is quite large in proportion. The artist used both thin bold lines in the painting. Particularly, the line used on the figure of Yamdutas is much thicker and bolder or harder than the lines used on the other figure drawings. The use of soft line and minimum use of cross, parallel and broken hatching in portraying the figure of Vishnudutas and Brahmins shows that they are the characters in the story of the painting with soft, mild, and godliness in nature with less muscularity and bulkiness in the body. It seems that the artist of this painting had tried to express not only the outer characteristic or the physical appearances of Puranic figures but also tried to express the nature of the individual personality with the use of different kind of lines, strokes and tones created through applying different 
type of hatching in the body. The small figure of the child Narayana placed in the middle of the painting creating a centre of interest in the composition. Artist creates some movements in the composition through the eyes of the Yamdutas and others which focusing towards the Ajamila. Beside this another movement can be viewed from the same angularity and direction of the feet of every human figure. Visually, this optical movement moving from right to left through the feet and from the feet connecting the direction of the eyes of the Yamdutas the movement comes back in the middle of the composition. The appearance of movement in the composition is one of the most important principles of the design of this composition which will help the audiences visually to concentrate, focus or to keep the visualization within the painting.

The second painted folio of this Bhagavata-Purana contained a composition of vignette designs in the whole folio (Fig.2). The foliages have been drawn in a systematic order of alternation. The alternate arrangement is followed by a repetition of the same style of foliages inside the arched shaped frame. All the flowers have been drawn with five petals instead of space remain for one more petals. It can be assumed that the Artist might have undoubtedly left to draw this one petal for the purpose of visualizing the sepal and receptacle part of the flowers. Two kinds of the flower have been introduced by the artist to decorate the whole painting of the folio. The basic colour of the flowers is red and white and green on the stem and leafs respectively which are contrasting with the yellow and red colour of the background. It is not certain to say that what types of flower and flowering plants that artist has tried to represent. The characteristic of the portrayed white flower (Fig.7) in the painting is somewhat close to the local "Nahor phol (Mesua ferrea or Ceylon Ironwood)" of Assam (Fig.8) and the red flower (Fig.9) is bear a resemblance to local "Dumboli or Bombax Ceiba" 8 or flowers of silk cotton tree (Fig.10). To maintain a balance and systematic order, the artist has incorporated two type of arch shape inside a rectangular shape. The arch shapes have been classified as round or semicircular arch (Fig.11) and ogee arch (Fig.12). The representation of arches with different floral designs in the painting may remind us of the style of alternative use of floral design in the wall of Hindu temples and in the Mughal art and architectures of India. As an example, such type of alternation of floral motifs had been used in the Mughal miniature paintings as well as in the arches and in the wall of Mughal architectures like Tajmahal. It may be possible that the artist of this Bhagavata painting might get influence from the contemporary Mughal style of paintings.

Relating to the depicted painting of Vaikuntha (Fig.3,) it has been observed that every object of the paintings particularly the image of Joy, Vijoy, Lord Vishnu and the two female attendants have been portrayed using bold lines. The frontal image of Lord Vishnu placed in the middle of the composition creates a visual attention and interest in the centre of the depicted painting. Similarly, the physical movement of the portrayed eyes and other body parts of the male and female attendants toward the Lord Vishnu also generate a visual or optical movement within the composition. Some unnatural movements of the foot and fingers have been observed in the figure drawings but the artist had maintained a balanced proportion in the depicted figures. Artist has introduced different types of the arch like architectural structure to frame 
out the individual male and female figures in the painting. These architectural arch frames can be classified as round (Fig.11), segmental (Fig.13) and Multi-foil (Fig.14). The systematic distribution of this architectural frame in the painting significantly balanced the composition of the painting. It is very interesting to notice that the portraying divine figure inside the different arched frame in the temple architecture and the style of representing the door and window in a round, segmental and multifoil remained a stylistic feature in the ancient and medieval tradition of architecture in Assam. As an example, such stylistic feature has been observed in the building of Kamakhya temple of Kamrup district ( $6^{\text {th }}$ century and rebuilt during 1565 by Koch king Naranarayana), Navagraha temple of Guwahati $\left(18^{\text {th }}\right.$ century during Rajeswar Singha), Shiva temple of Sivsagar (1734) during Siba Singha, Charaide (1228 A.D) (burial of the Ahom king), Rang Ghar of Sivsagar ( $18^{\text {th }}$ century during Pramatta Singha), Kareng Ghar built by Rudra Singha etc. In the account of the architectural drawing introduced in the painting may be the resultant of the artist's influence from the old and contemporary architectures of the Ahom kingdoms. However, in terms of composition, the artist had represented a quality of aesthetical sense of the repeated arrangement of the architectural shapes with the divine figure drawings in the paintings. Observing the style and introduction of the elements like maximum use of bold black outlines in all the figure drawings, architectural shapes, garments and ornaments, absent of floral designs surrounding the depicted scene, the furious facial expression, unnatural drawing and movement of fingers and dissimilarities in the distribution of floral motifs in space against the red background without any detailing and outlines as used in the other floral designs of the painted folios suggest that the painting of the scene of Vaikuntha may be the work done by another artist. It is quite possible to think and say that the paintings of this book Bhagavata- Purana VI-VII are the contributed work of more than one artist and they were influenced by the Persian or Mughal art of paintings or they were the court artist of the Ahom kingdom.

\subsection{Different kind Puthi-nabhi designs:}

A hole which has been made at the middle point of the manuscripts commonly called as Puthi-nabhi. It is a hole used for tying up the folios together. This is a traditional system of binding manuscripts in Assam. However, representation of colourful flowerlike design surrounding a Nabhi can be called as Puthi-nabhi design.

This present volume of Bhagavata VI-VII has been found with different kinds of Puthi-nabhi design. Almost all the Puthi-nabhi of each folio has been encircled a distinctive design except three single folios of thematic painting (Fig. 15, 16, 17, 18). The way of representation and introduction of flower-like motifs in the individual Nabhi designs are different. The designs are depicted in square, rectangular and in circular shapes inside which a flower like motifs have been drawn keeping nabhi in the centre. Visually the Nabhi appears and representing the core or centre part of a flower. These puthi-nabhi designs consist of a systematic arrangement of vertical \& horizontal lines, zigzag, and curved, angular, and wavy lines. Red, yellow, green, white, orange, pink and black with their different tint shade have been used to draw the designs. Black, red, yellow, and brown colour has been used to draw the outline on the individual motifs. A single flower bearing plant is also depicted in a Puthi-nabhi design. The position of colourful Puthi-nabhi designs in the middle of the scripts or folios creates a 
focusing point in between the folios which high up the aesthetical quality of the overall compositional arrangement of these scriptural folios.

\subsection{Distribution of Colour in the paintings}

The colours commonly used in the painting are yellow, brown or umber, Blue, Green, Red, black and white. Besides the use of different types of hatching to get the volume of the figures, the artist also used some strokes with dark shaded colour. Artist has kept some tonal effect of Blue-violet to represent the skin complexion of the Vishnuduta's. The upper garments of the Vishnu imageries have been represented in white colour with the decoration of red rose like floral motifs on it. The ripple folds of the upper and lower garments are expressed using red thin flowing lines. Some angular and cross-hatchings have been also used on the lower garments of the figures which create some gradation on the ripple of the garments. The white and yellow colour used on the painting is contrasting with the flat red colour of the background. The use of green colour in the painting is less compare to other colours. Specifically, green colour has been used on the necklace of the Vishnu imageries and on the floral border design around the painting. It is very interesting to notice that, the artist distributed the two important colours red and yellow alternately in these paintings. The red has been used in the background part of the main subject of this painting and yellow being the highlighted or contrasting part upon red. In the same way, the yellow has been used, placed or kept in the background part of the red, green floral decorated design for the framing. This alternative use of yellow and red also claim to an appreciable artistic quality in balancing the composition of colour.

2.6. Classification of colours from the paintings

$$
\text { 2.6.1. Red }
$$

Red is one of most common colour in the traditional colour palette of manuscript painting in Assam. The source of this Red colour is the natural ingredient Hengul or Hingul (Fig.19). Author D. Nath mentioned in the book "History of the Koch kingdom" that Hengul stands for Vermillion. This shade of red may be considered as a dark vermilion or can be classified or assumed as red-orange or the colour between scarlet to brick-red. There is a variety of red colour used to be found and observed in the manuscript paintings of Assam. But it is not much known that how the different variations of red colour had been produced by the artist. It has been studied that in the tradition of manuscript painting in Assam "Lac dye or Alta was used to obtain a deep and rich red". ${ }^{9}$ Here, it is quite possible that the painter or the artist might have mixed Alta with the powder of Hengul to get the desire deep and rich red for the background of this painting. So that the neighboring colours like yellow, white, dark brown, black and blue used on the painting may form a greater contrast or a quality of contrast in the painting. In the same way, this Lac dye spoken as Alto has been popularly used in the tradition of western Indian painting to get the desire rich and deep red of Vermillion. Varieties of red colour have been used and commonly visible almost in every folio of the Bhagavata-Purana VI-VII. 


\subsubsection{Yellow}

The yellow of Haital or Harital (Fig.20) is another most important colour of the traditional colour palates of manuscript painting in Assam. There is an application of a variety of yellow colour in all the three paintings and in the decorated floral border designs in every folio can be observed. It can be said as yellow with high, medium and low intensity or luminosity in character and farther can be classified as the colour between highlighted or bright yellow to dark as yellow ochre. Artistically, it is quite possible that the artist might be used or mixed white with the yellow in the desired quantity to get the different variety of tint colour of yellow and luminosity in the painting. Such as the yellow of the lower garments of the first two Yamdutas from the left side can be classified as yellow with high brilliancy compare to yellow used on the garments of third imageries of Yamduta. Besides the use of tint colour of yellow, the artist had also used another variety of yellow to depict the skin complexion of the images of Ajamila \& Narayana of the first Painting and on the images of Joy, Bijoy and two ladies of the third paintings which can be classified as reddish-yellow in a combination of white. These varieties of yellow used and distributed in the paintings are much more contrasting and highlighted part of the painting then the other distributed colours. There are many variations of yellow have been used by the artist in the paintings of Bhagavata-Purana VI-VII and most common in every folio of the book.

\subsubsection{Brown}

The colour has been classified as a dark shade of brown colour (Fig.21). The Artist possibly obtained this dark brown colour by mixing desire amount of natural Black or lamp black, with the red of Haital and little yellow of Hengul. This dark-brown colour has been specifically used to get the desire aesthetic value of dark skin complexion of the three Yamdutas only.

\subsubsection{Green}

In general green is a type of binary or secondary colour obtained by mixing equal ratio of two primary colours yellow and blue (Fig.22). In the paintings of this BhagavataPurana VI-VII different variations in the application of green colour has been observed. Particularly, green have been used in the floral border design around the paintings and on the upper garments of the three Vishnu imageries as well as on the garland. Moreover there is a much variation in using green colour has been observed in the decorative designs of different foliages and also used in decorating the Puthinabhi. Darker and lighter variation of green has been used to paint leafs of the flowerbearing plants. The artist has maintained a principle elements repetition and alternation in using two variants of dark and light green colour to depict the six flower-bearing plants repeatedly and alternately. That is the systematic arrangement of six plants with alternate distribution of three plant bearing dark green leafs and another three plants with light green leafs. This organized distribution of green helps to create and maintain an artistic quality of colour balance within the composition. The use of black outline with modeling on the dark green leafs and yellow outline with modeling on the light green leafs makes the appearances of two individual green colour more prominent. Though the dark green comes into view with more contrast 
against the yellow colour of the background whereas the light green leafs with yellow outline and modelings appears less prominent and contrast against the red of the background. But the equal alternative and repetitive quality of contrast also makes the painting visually balanced. Moreover the artist had used only dark green colour to give a picture of leafs in the border design around the painting.

Another variation of green colour has been used in the folio contain a picture of Vaikuntha scene. It is a type of green may be obtained by the combination of desire amount of Green and black and it has been identified as a blackish-green. This blackish green is prominently used flat in the rectangular border or margin around the painting. This blackish-green is also used to depict the steps in the lower middle part of the composition upon which the seated image of Vishnu has been portrayed. It has been observed that the use of blackish-green has high up the weight of composition in the lower middle part and much more contrasting with the other red, yellow, white and blue colour of the painting. The application of much more dark green colour in the lower middle does not cause any visual interruption in balancing the composition. However, a variety of green colour has been classified from the paintings of BhagavataPurana VI-VII such as Blackish-green, Dark-green, Yellow-green, light yellow-green, Bluish- Green etc.

$$
\text { 2.6.5. Blue }
$$

The use of blue colour (Fig.23) is less in the paintings. Blue is used to depict the skin complexion of the seated image of Vishnu and on the three Vishnu imageries. Though both the blue colour complexion is not same and appears with a variation of lightness. Particularly the bluish complexions of the three imageries are lighter than that of the seated image of Vishnu in the other folio. Some tonal effect of blue has been observed on the skin complexion of three imageries where as the blue of the seated image of Vishnu appears flat and deep. Another variation has been observed in the Puthi-nabhi design which appears like greenish blue. The application of blue and its variation is quite minimal compared to other colours. Variation like grayish-blue is also observed in the marginal or border floral design in some folios and particularly used to paint leafs.

\subsubsection{White}

The use of white (Fig.24) appears as one of the most contrasting colour with a systematic order of distribution. Application of fresh white is specific and prominent to depict some objects in the composition of paintings. White is applied on the upper garments (dupatta) of the four Vishnu imageries which help to highlight the placement of four godly forms in the arrangement of the composition. The white with same intensity have been distributed on the large eyes and teeth's of the three Yamdutas. White is also used to represent the hand tying ropes of Ajamila. This selective area of white appears most contrasting and highlighted parts of the painting. Similarly, the white used on the painting based on only foliage particularly on the depiction of flowers is also appears with a quality of contrast among the other distributed colour. Repetitive and alternative distribution of white creates a visual concentration in between painting. Basically white is used to depict the petals and 
core part of the flowers. In Vaikuntha painting, white is used to visualize the upper garments of one of the gate keepers on the left and on the wearing shawl of side faced knee bending seated women figure on the lower left middle part of the painting. The bow of violin in the lower right middle part is also portrayed in white colour. Beside this selective distribution, white is most prominent, contrasting and highlighted in the upper middle part of the composition. In particular, the two pillars and arches of the architectural compartment between which the seated image of Lord Vishnu have been depicted. Other four pillars of the two architectural compartments on the right and left to middle compartment or chamber of Vishnu are also painted in white but not the upper arches as painted for the middle chamber of Vishnu.

In the distribution of colour for the arrangement of composition artist have tried to create or give more focus in the middle where the image of Vishnu has been positioned. So that the white as a much more highlighted and contrasting colour compared to other colour of the painting has been used to indicate the position where the main and central figure of Vishnu has been placed. White is also used to indicate the two vertical parallel marks put on the four hands and chest of the depicted image of Vishnu. The expressive large eyes and narrow dupatta have been painted using white. Moreover the application of white attaching the upper middle part of the pillars of the middle chamber is also appears with more brightness and contrast. Hence the distribution of more white in and around the middle chamber creates a centre of interest in the composition.

$$
\text { 2.6.7. Black }
$$

Black (Fig.25) is the most significant colour in the paintings of Bhagavata VI-VII. The artist might be used black, red, yellow to made dark brown colour which is the skin colour complexion of the three Yamduttas. The bulkiness of the muscles of three Yamduttas has been visualized by using black colour. The wavy hair, toned muscles, large moustaches, eyebrows, weapons like Gada (mace) has been depicted in black. As usual Black is specific in use to represent the colour of the hair of all the male and female figures of the individual paintings. Moreover black is used in outlining the maximum objects in the composition such as different body parts of the image of Vishnu, green garland, architectural chambers, garments, ornaments and on the border floral designs. Application of black creates and gives some dimensional effect to the floral designs especially on the representation of leafs. Artist has used different techniques to introduce black colour to get the desired volume, and contrast such as the cross-sectional hatching, straight hatching, diagonal hatching, bold, sharp \& thin flowing lines and might be mixed up with other colour to get different variations and intensity in the distribution of colours.

\section{List of Figures}

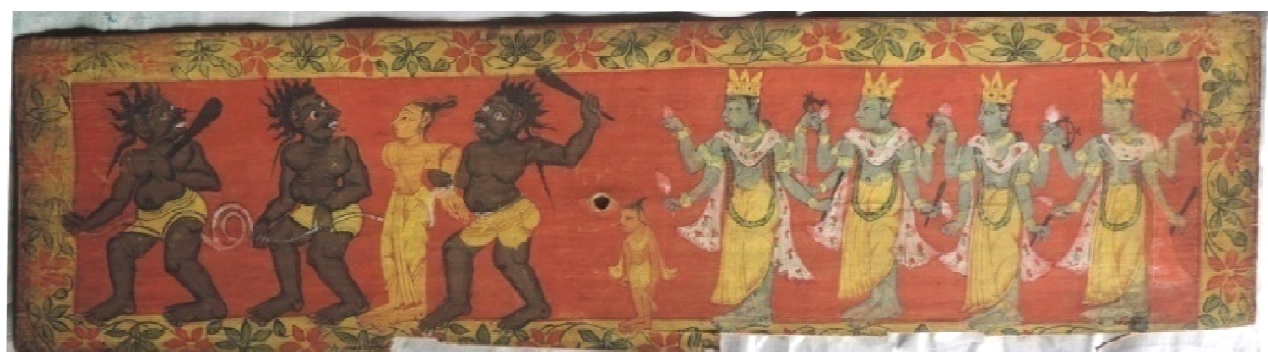


Figure 1: Title of the manuscript volume: Bhagavata-Purana, VI-VII, Subject of the painting: Rescue of the departing body of Brahmin Ajamila by the messengers of Lord Vishnu, Medium: Natural colour on Sanchipat (Bark of Aloe wood), Size of the painting: 39.3X $11 \mathrm{Cm}$. Find place: Karchong Sattra (Vaisnava Monasteries) of Nagaon district in Assam, India, Photography by: Bikramjit Sarkar (Author), 2016, Courtesy : SSRI (Srimanta Sankardev Research Institute), Nagaon, Assam, India. Year of Execution: 1785 A.D.

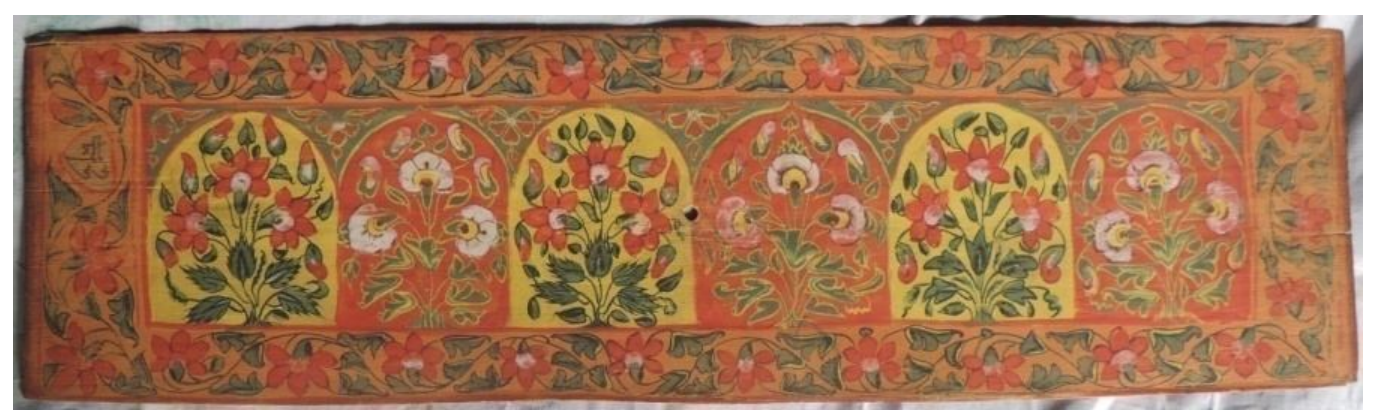

Figure 2: Title of the manuscript volume: Bhagavata-Purana, VI-VII, Subject of the painting: Arrangement of Floral design, Medium: Natural colour on Sanchipat (Bark of Aloe wood), Size of the painting: $39.3 \mathrm{X} 11 \mathrm{Cm}$. Find place: Karchong Sattra (Vaisnava Monasteries) of Nagaon district in Assam, India, Photography by: Bikramjit Sarkar (Author), 2016, Courtesy: SSRI (Srimanta Sankardev Research Institute), Nagaon, Assam, India. Year of Execution: 1785 A.D.

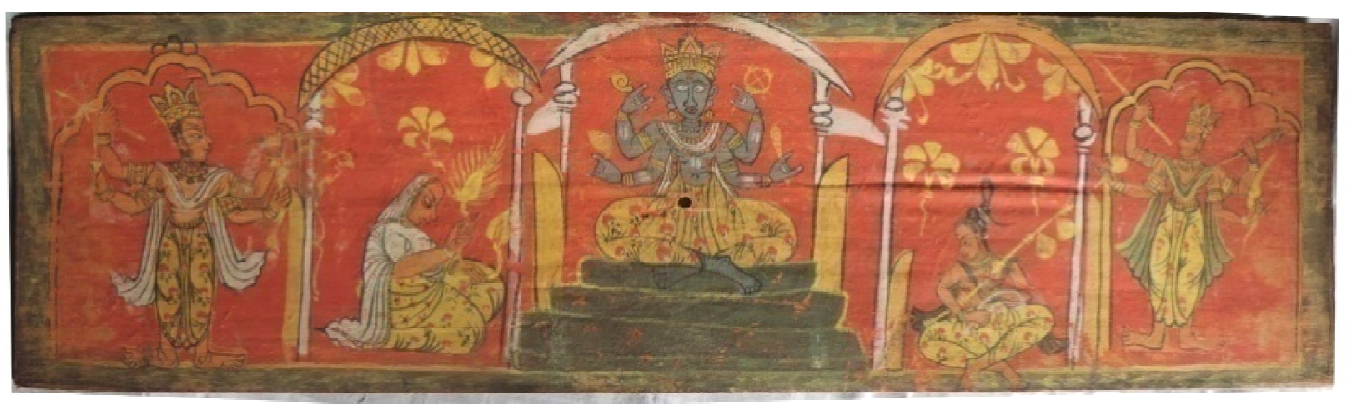

Figure 3: Title of the manuscript volume: Bhagavata-Purana, VI-VII, Subject of the painting: Arrangement of Floral design, Medium: Natural colour on Sanchipat (Bark of Aloe wood), Size of the painting: 39.3X $11 \mathrm{Cm}$. Find place: Karchong Sattra (Vaisnava Monasteries) of Nagaon district in Assam, India, Photography by: Bikramjit Sarkar (Author), 2016, Courtesy: SSRI (Srimanta Sankardev Research Institute), Nagaon, Assam, India. Year of Execution: 1785 A.D.

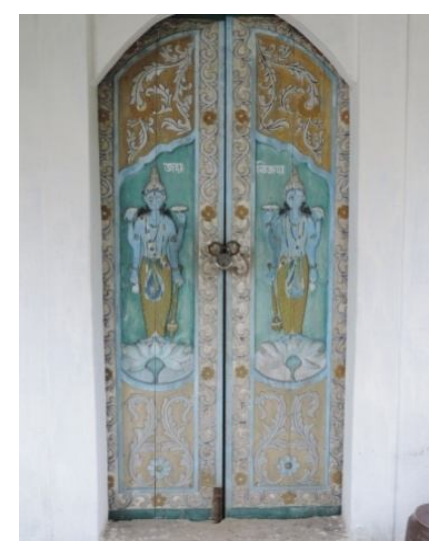

Figure 4: Title: Wood carving image of Jay and Vioy in door of Ganakkuchi Sattra, District: Barpeta, Assam, India. Photography by: Bikramjit sarkar (Author), 2016. Courtesy: Authority Ganakkuchi Sattra, Assam.

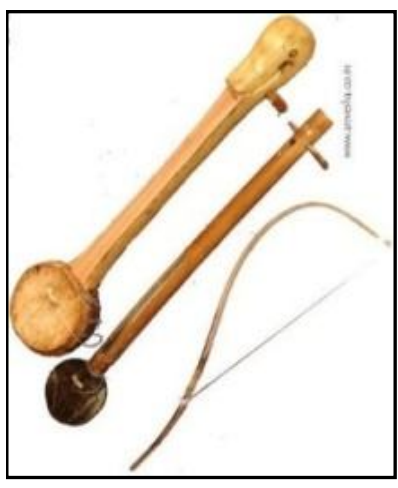

Figure 5: Assamese Traditional musical Instrument called Bin. Source:

www.anvesha.co.in/bin_en.htm Date: 09/03/2017 


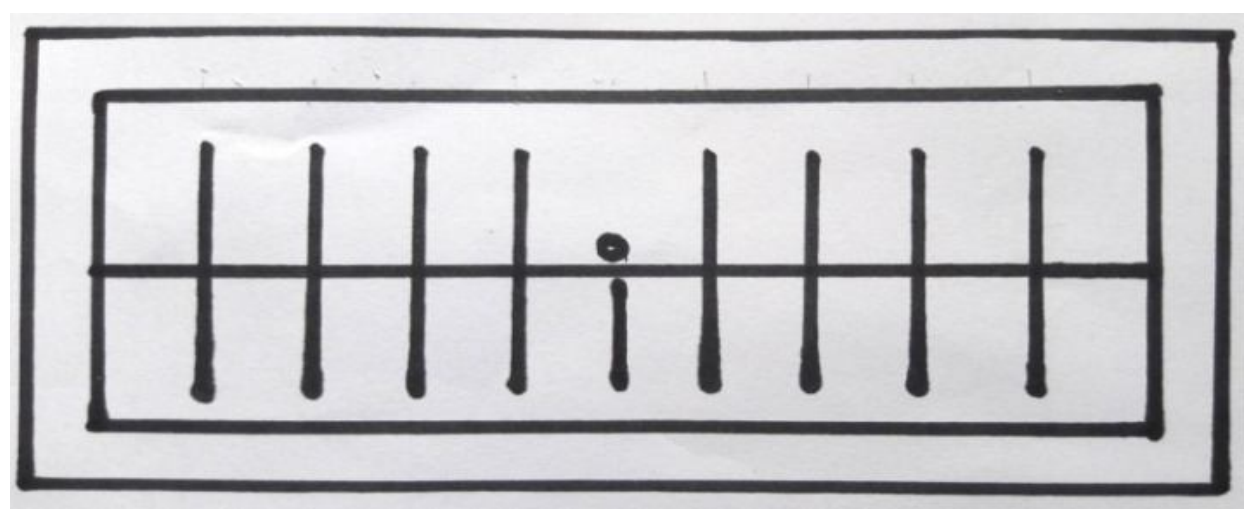

Figure 6: Graphical representation of the composition (Figure. 1) By: Author (self), Date: 10/11/2016

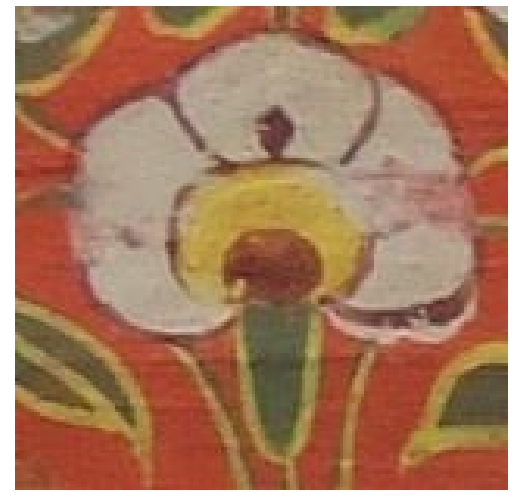

Figure 7: Name: Unknown Flower, Source: Bhagavata- Purana, VI-VII, Photograph Edited by: Author (Self), Date: 18/11/2016

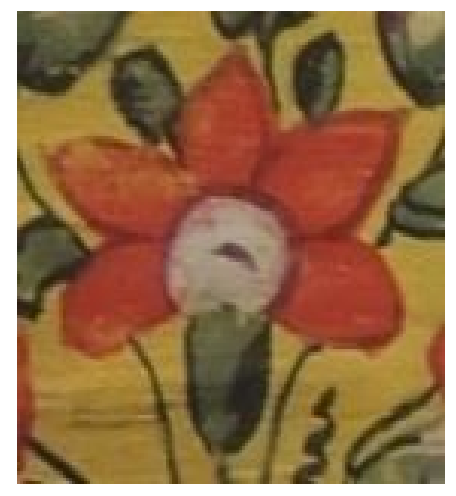

Figure 9: Name: Unknown Flower, Source: BhagavataPurana, VI-VII, Photograph Edited: Author (Self), Date: $18 / 11 / 2016$

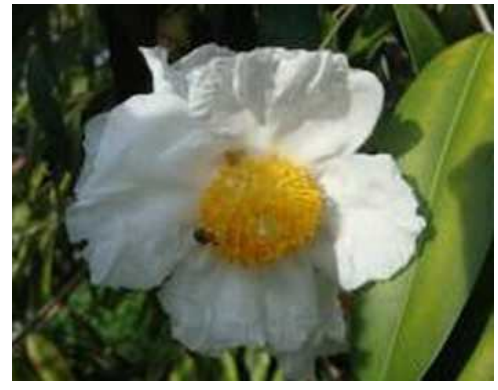

Figure 8: Local name: Nahor Phol (Mesuaferrea) or Ceylon ironwood, Source of Photograph: www.whatiscalled.com/flowernames-in-assamese/pag=3/, Date: $09 / 03 / 2017$

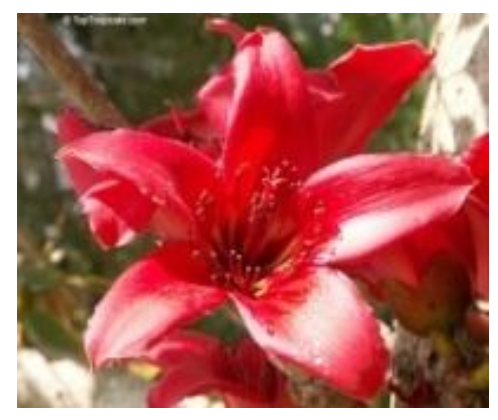

Figure 10: Name: Bombax ceiba flower, Local name: Dumboli Phol or Simolu Phol, Source of photograph: toptropicals.com/catalog/uid/bombax_c eiba,htm, 09/03/2017 
52 The Art of Traditional Painting in Assam: a Critical Study on the Manuscript

Paintings of Bhagavata-Purana, VI-VII

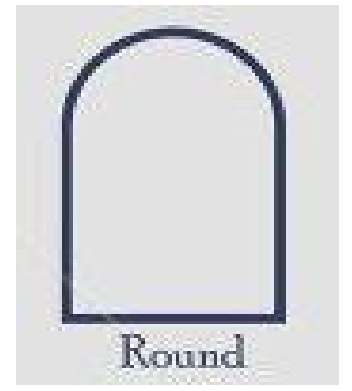

Figure 11: Name: Round arch, Source:

www.shutterstock.com, Date: 09/03/2017

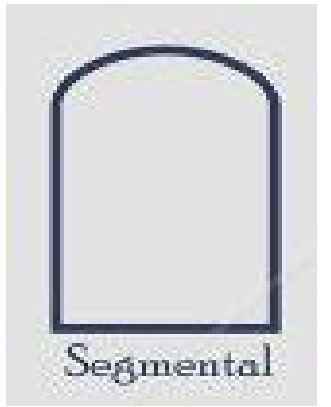

Figure 13: Name: Segmental arch,

Source:

www.shutterstock.co

m, Date: 09/03/2017

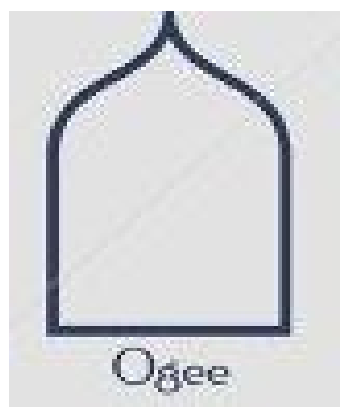

Figure 12: Name: Ogee arch, Source:

www.shutterstock.com, Date: 09/03/2017

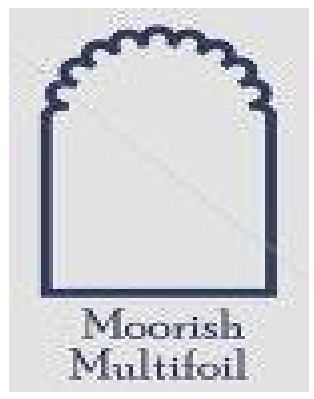

Figure 14: Name: Moorish Multifoil arch, Source: www.shutterstock.com, date: 09/03/2017

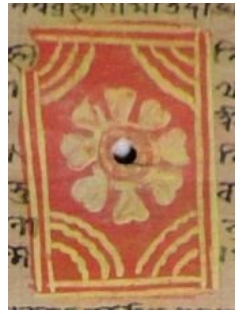

Figure 15: Name: Puthi-Nabhi design, Source: From the original photograph of Bhagavata-Purana, VI-VII, Edited by Author, date: 09/03/2017

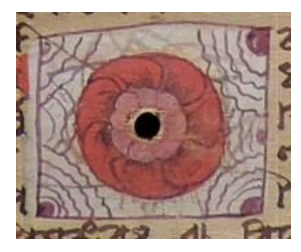

Figure 16: Name: Puthi-Nabhi design, Source: From the original photograph of Bhagavata-Purana, VI-VII, Edited by Author, date: 09/03/2017

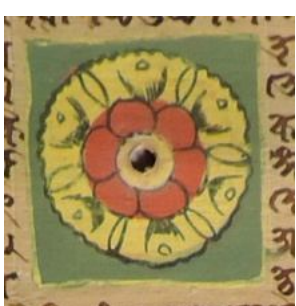

Figure 17: Name: PuthiNabhi design, Source: From the original photograph of Bhagavata-Purana, VIVII, Edited by Author, date: 09/03/2017

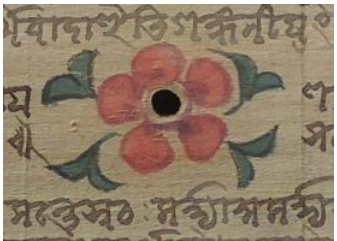

Figure 18: Name: Puthi-Nabhi design, Source: From the original photograph of Bhagavata-Purana, VI-VII, Edited by Author, date: 09/03/2017 


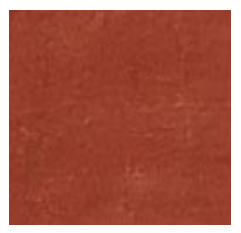

Figure 19: Name: The image represents red of natural Hengul (Vermilion or red arsenic) Source: Classified from the original photograph of paintings of Bhagavata-Purana, VI-VII, Edited by Author, date: 09/03/2017

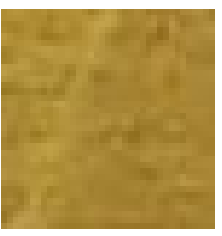

Figure 20: Name: The image represents yellow of natural Haital (yellow arsenic) Source: Classified from the original photograph of paintings of Bhagavata-Purana, VI-VII, Edited by Author, date: 09/03/2017

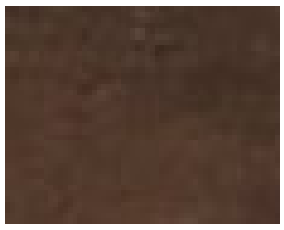

Figure 21: Name: The image represents Brown colour colour used in the paintings, Source: Classified from the original photograph of the paintings of Bhagavata-Purana, VI-VII, Edited by Author, date: 09/03/2017

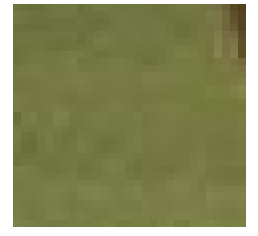

Figure 22: Name: Green used in the painting by mixing Haital and blue of indigo, Source: Classified from the original photograph of the paintings of Bhagavata-Purana, VI-VII, Edited by Author, date: 09/03/2017

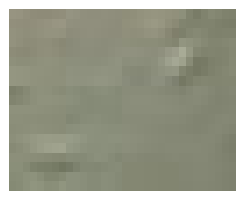

Figure 23: Name: The image represents blue of Indigo (natural colour used in the paintings), Source: From the original photograph of Bhagavata-Purana, VI-VII, Edited by Author, date: 09/03/2017

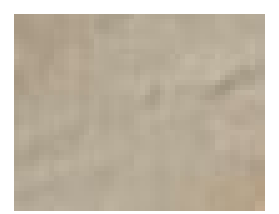

Figure 24: Name: The image represents white of Dholmati (Earth colour) used in the paintings, Source: From the original photograph of Bhagavata-Purana, VI-VII, Edited by Author, date: 09/03/2017

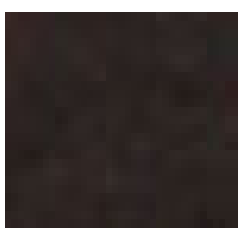

Figure 25: Name: The image represents lamp black (natural colour used in the paintings), Source: From the original photograph of Bhagavata-Purana, VI-VII, Edited by Author, date: 09/03/2017

\section{Conclusion}

The paintings of this Bhagavata-Purana represent different stylistic features of the early and contemporary art of Assam and other painting schools of India such as the introduction of floral decorative border design around the paintings and inside architectural arch frames which also remained as one of the important stylistic features in the Mughal and Jain tradition of paintings. The artist has maintained the local stylistic features of the composition of both object and subjects against the flat red and yellow colour background of the Satriya style of paintings. The paintings give the visual representation of the divine beings of Hinduism. Through these paintings, artists have represented different elements, principle and techniques and their way of traditional arrangements. The paintings give the visual representation of the stories related to Lord Vishnu. The artists have introduced his skill and aesthetic sense of 
vision by arranging different elements of art and principle in a system of repetition and alternation which high up the beauty of the thoughts of Bhagavata-Purana in visual form. The most appreciable and significant characteristic is the traditional process and the use of natural ingredients as a medium of paintings so that the paintings were still looking fresh even after 232 years of its execution. It is most important for any artist to be conscious about longevity and durability of his/her creations so that the next generation of artist and art lovers can get the knowledge, influence and be aware of the existence of past art and culture of a region. In the present time of globalization, these manuscript paintings represent the Vaishnavite culture of traditional art practice of $18^{\text {th }}$ century Assam as well represent the culture of painting in North-East India.

\section{References:}

Abhijit \& Jiten. (2017). BIN, www.anvesha.co.in/bin_en.htm, 09/03/2017

Dasgupta, R., (1972). Eastern Indian manuscript painting, D.B. Taraporevala sons \& co. Pvt. Ltd., Bombay, 1972, pp.103.

Dasgupta, R., (1972). Eastern Indian manuscript Paintings, D.B.Taraporevala sons \& co. Pvt. Ltd.

Goswami, H.C. (1930). Descriptive Catalogue of Assamese Manuscripts, D.H.A.S, Assam

Kalita, N. (2009). An Alphabetical Index of Illustrated manuscripts of Assam, IGNCA, New Delhi, PP.61

Nath, D. (2016). Religious tradition and Social Practices in Assam, Guwahati, DVS Publisher, pp. 219

Wikipedia. (2017). 'Fly-whisk', https://en.wikipedia.org/wiki/Fly-whisk), 05/o1/2017

www.flowersofindia_net. (2008). Bombax ceiba-Silk Cotton Tree- Flowers of India, www.flowersofindia.net, 2008

www.whatiscalled.com. (217). 'Ceylon Ironwood in Assamese', retrieved from www.whatiscalled.com/flower-names-in-assamese/pag=3/, 09/03/2017 